Article

\title{
A Validation and Cost-Analysis Study of a Targeted School-Based Dental Check-Up Intervention: Children's Dental Program
}

\author{
Tan Minh Nguyen ${ }^{1,2,3, *(\mathbb{D})}$, Bradley Christian ${ }^{4,5}$, Sajeev Koshy ${ }^{6}$ and Michael Vivian Morgan ${ }^{7}$ \\ 1 Deakin Health Economics, Institute of Health Transformation, Faculty of Health, Deakin University, \\ Waurn Ponds, VIC 3216, Australia \\ 2 Community Dental Program, Peninsula Health, Frankston, VIC 3199, Australia \\ 3 Coburg Hill Oral Care, Coburg North, VIC 3058, Australia \\ 4 Dentistry and Oral Health, La Trobe Rural Health School, La Trobe University, \\ Bundoora, VIC 3552, Australia; b.christian@latrobe.edu.au \\ 5 Centre for Oral Health Outcomes \& Research Translation (COHORT), School of Nursing \& Midwifery, \\ Western Sydney University, Sydney, NSW 2751, Australia \\ 6 Dental Health Services Victoria, Carlton, VIC 3053, Australia; sajeev.koshy@dhsv.org.au \\ 7 Faculty of Dentistry, University of Otago, Dunedin 9016, New Zealand; mike.morgan@otago.ac.nz \\ * Correspondence: tan.nguyen@deakin.edu.au; Tel.: +61-432-715-420
}

Received: 13 October 2020; Accepted: 23 November 2020; Published: 26 November 2020

\begin{abstract}
Background: Limited evidence exists to inform best practice approaches to implement school-based dental screening to address child retention via referral for dental services. This research tested the null hypothesis that a targeted school-based dental check-up program (intervention) has a $75 \%$ child retention rate for public dental care $\left(\mathrm{H}_{0}=0.75\right)$. Methods: A prospective non-randomised controlled trial was conducted with a convenience sampling approach in metropolitan Melbourne, Australia. Children in the intervention group were recruited from two preschools and two primary schools from a low socioeconomic area. Children in the standard care group were recruited from the local public dental service. Statistical analysis was performed using Stata IC Version 12. Results: Children in the intervention ( $45 \%$ ) were significantly less likely to have never had a dental check-up compared to standard care $(20 \%)(p<0.001)$. There was no significant difference for the child retention rate for the intervention group when compared against the null hypothesis $(p=0.954)$. The total society costs were AU $\$ 754.7$ and AU $\$ 612.2$ for the intervention and standard care groups, respectively $(p=0.049)$. Conclusions: This validation study provides evidence that a targeted school-based dental check-up program can achieve a $75 \%$ child retention rate and should be considered for program expansion.
\end{abstract}

Keywords: dental care for children; school health services; oral health; preventive health services; costs and cost analysis

\section{Introduction}

Untreated childhood dental caries in the deciduous dentition is the 10th most prevalent health condition affecting $9.0 \%$ of the global child population in 2010 and its prevalence has remained relatively unchanged [1]. In Australia, 27.1\% of children aged 5-10 have untreated dental caries in the deciduous dentition and $10.9 \%$ of children aged $6-14$ years have untreated dental caries in the permanent dentition [2]. Children less than ten years of age experience a high burden of potentially preventable hospitalisations due to poor oral health in comparison to all other age groups [3]. 
Despite most Australian children being eligible to receive free or low-cost dental care within the public sector, the dental care utilisation rate among children has remained proportionately low. Population oral health surveillance data shows that $57.4 \%$ of children aged $13-14$ years have never visited a dental practitioner before age 5 [2]. Among children aged 2-17 years from low-income families, only $37.9 \%$ of children eligible under the Child Dental Benefits Scheme (CDBS) have claimed benefits under the program [4]. The CDBS is a means-tested Australian federal government program, which provides up to AU $\$ 1000$ value of dental services over a two-year period.

Traditionally, school dental screening programs have been implemented to address oral health inequities, particularly for children from low-income families who are at increased risk for dental caries. There is limited high-quality evidence to support this type of public health intervention in increasing dental care utilisation, and for its effectiveness to improve childhood oral health $[5,6]$. Several studies have reported that the proportion of children returning for dental treatment via referral from school dental screening programs can be up to $50 \%$ [7].

Different approaches to school dental screening have been trialled. It can yield high levels of child participation at the start, but the child retention rate for dental treatment via referral dropped significantly from $81 \%$ to $40 \%$ [8]. From a health economics perspective, the opportunity costs lost where there is limited benefit to society when compared to an alternative public health intervention is an important consideration for resource allocation and policy decision-makers.

However, school settings remain an important environment to support childhood health and wellbeing. They include the utilisation of school nurses for physical and mental health support $[9,10]$ and public health policies for school-based vaccinations [11]. Given that family-level characteristics have an influential role in children's oral health [12], interventions that include the primary carer in the oral health management of the child within school settings should be further investigated.

Previous work has demonstrated that a pilot school-based dental check-up program could achieve a child retention rate of $74 \%$ [7], and that the program was less costly and more effective than standard care [13]. In contrast to school dental screening, where the primary carer is often absent, a targeted school-based dental check-up program is a point of difference since it is mandatory for the primary carer to accompany their child at the school premise.

There are other important psychosocial considerations that support why maintaining optimal oral health to children is essential. A previous history of utilising school-based dental services has been associated with a reduction of dental fear and anxiety in adulthood [14]. Improved children's oral health may also have a role in addressing known associations between untreated dental caries, poor school performance and poor school attendance $[15,16]$.

Healthy weight according to the Body Mass Index (BMI) among children may also be protective against dental caries [17] and impact on a child's ability to perform everyday activities. However, there is a limited understanding whether there are differences in healthy weight and dental pain experienced by children who are more frequent users of Australian public dental services than those who are not.

The primary aim of this research is to validate the null hypothesis, based on previous published work [13], that a targeted school-based dental check-up program (intervention) can achieve a child retention rate of $75 \%$ for public dental care $\left(\mathrm{H}_{0}=0.75\right)$ at a two-year follow-up. A secondary objective is to perform a cost-analysis of the intervention from a societal perspective in comparison to standard care at an Australian public dental service. These outcomes are important for health economic modelling and resource allocation decision-making.

\section{Materials and Methods}

\subsection{Study Design and Target Population}

A prospective non-randomised controlled trial was conducted with convenience sampling between 2016 and 2019. This research received Human Research Ethics Approval from the University of Melbourne (HREC 1441662.2). 
For the intervention group, children aged 3-12 years who were enrolled in two preschools and two primary schools were invited to participate. The schools were located in a suburb with the lowest 10th percentile for Socio-Economic Index For Areas (SEIFA) index [18] in the geographical region of the City of Whittlesea, $20 \mathrm{~km}$ north of Melbourne, Victoria, Australia.

For the standard care group, children from the same age range were recruited by the local public dental service, which provides community healthcare services, including dental services, to residents living in the City of Whittlesea. Children in both groups who have received a dental check-up within the last three months were excluded in this study.

For economic evaluation studies using cost-effectiveness or cost-utility analysis, the focus is to identify whether an alternative intervention should be adopted or not from the cost perspective, rather than to replace an existing intervention. However, other implementation considerations such as health equity may be an important contextual concern for policy decision-makers. Therefore, the sociodemographic profile for both the intervention and standard care groups was explored but not used as a selection criterion.

\subsection{Sample Size}

A minimum of 288 children for each group was required to test the null hypothesis $\left(\mathrm{H}_{0}=0.75\right.$; $95 \%$ confidence; $\pm 5 \%$ proportion range) [19]. Child retention was defined as whether a child in the intervention group who required referral had attended at least an additional dental appointment at the local public dental service by the end of the two-year follow-up.

As a comparator, child retention in the standard care group was determined if the child attended at least an additional dental appointment for dental treatment. In some circumstances, dental treatment for children was provided at the first dental check-up visit due to the convenience of being present at the dental clinic.

\subsection{Training and Calibration}

To minimise the inconvenience to potential participants, calibration for the dental examinations were performed ex vivo rather than in vivo. A combination of 16 tooth surfaces from 16 extracted deciduous and permanent teeth, sterilised and placed on an individual cast, were scored by a gold standard examiner (H.C.).

Three dental examiners (T.M.N., M.N. and C.E.) were trained and calibrated using the modified International Caries Detection and Assessment System II (ICDAS) tool. Code 1 was excluded since the availability of triplex air to dry and assess the teeth for the intervention group was not available. Untreated dental caries at baseline were diagnosed at $d / D_{3}-d / D_{6}$ level, i.e., being diagnosed at least to the severity of cavitated enamel caries for the deciduous and permanent teeth. Dental examiners scored a random combination of the tooth surfaces with the teeth wet on three separate days using a portable headlight, intra-oral mirror, periodontal probe and gauze.

The two-digit recording system was used to establish intra- and inter-rater reliability according to the ICDAS Committee recommendations [20]. The intra-examiner Kappa score ranged between 0.64 and 1.00 and the inter-examiner Kappa score ranged between 0.62 and 0.80 when compared against the gold standard examiner.

T.M.N. and L.N. performed dental check-ups for the intervention group. L.N. and C.E. conducted the dental check-ups for the standard care group. At the two-year follow-up data collection, untreated cavitated dental caries were recorded by uncalibrated dental practitioners within the public dental service for both the intervention and standard care group, assumed to be within dentine. This intentional pragmatic approach minimised the administration burden to the local public dental service and acknowledges the value of a 'natural' experiment. 


\subsection{The Intervention}

For the intervention group, children were recruited up to four weeks in advance to a scheduled study visit. Primary carers could contact the local public dental service or were contacted upon a signed consent form returned from school. Interpreters were arranged where appropriate using the school's existing interpreter services.

The dental check-up involved children seated in an age-appropriate chair. Calibrated dental examiners performed the dental check-up using portable dental equipment following relevant infection control procedures.

It was mandatory that the primary carer attended the child's school-based dental check-up appointment. Children recommended for further dental treatment, a 'positive' referral, had follow-up calls made by the local public dental service to arrange an additional dental appointment for dental treatment. Alternatively, primary carers could actively call the local public dental service. Children having a 'positive' referral received dental treatment following standard care. Children with a 'negative' referral were placed on six-month recall for a routine dental check-up.

\subsection{Standard Care}

Children recruited in the standard care group occurred when they had a routine dental check-up scheduled at the local public dental service. Children who did not require dental treatment were placed on either a 12-month, 18-month or 24-month recall for a routine dental check-up according to the local public dental service clinical guidelines.

\subsection{Data Collection}

A semi-structured questionnaire assisted by dental support staff was administered to participants and recorded the social and dental history (Appendix A Figure A1). They included:

- Previous history of the last dental visit,

- Household income,

- Card-holder status (eligibility for subsidised publicly funded healthcare),

- $\quad$ Eligibility for the CDBS, and

- Cultural background classified using the Australian Standard Classification of Cultural and Ethnic Groups (ASCCEG) [21].

Quality of life data were collected for 7-12-year-olds from both groups using the EQ-5D-Y self-rated questionnaire [22] (Appendix A Table A1 and Figure A2). The participants' self-rated general health was recorded using the EQ visual analogue scale (EQ VAS). The health profiles and EQ VAS data were reported using the recommended guidelines [22].

The EQ-5D-Y was planned to be used for economic evaluation. However, this is not possible at the time of writing [23]. The results of the EQ-5D-Y are presented to provide a comparison of the perceived general health quality of life between the intervention and standard care groups.

Untreated dental caries was recorded as being at least cavitated at baseline (ICDAS $\geq 3$ ) (Appendix A Figure A3). In-depth analysis of dental services received by children and the teeth health transition states will be reported in another paper focusing on the health economics perspective.

The child's height and weight were measured using a measure tape and household weight scale. Data input for the child's height and weight were classified using an Australian online healthy weight calculator using the US Centres for Disease Control and Prevention's BMI-for-age charts [24] (Appendix A Table A2). A category for 'Unhealthy Weight' was developed as the combined weight status of 'Below Healthy Weight', 'Above Healthy Weight' and 'Well Above Healthy Weight'.

For the two-year follow-up evaluation, a record audit was performed by TMN regarding:

- Date of birth,

- Sex, 
- Principle place of residence classified using the SEIFA index [18],

- Dental referral/treatment required after a dental check-up,

- Whether the child received any restorations or extractions for dental caries,

- The status if the child's dental treatment plan was completed,

- Dental treatment time,

- Number of dental visits,

- The number and type of dental treatment services provided according to the Australian Schedule of Dental Services and Glossary [25], and

- The prevalence of untreated and treated dental caries (in units of teeth).

\subsection{Cost-Analysis}

The method to calculate the total society costs, which includes the cost components for travel, dental treatment, and opportunity costs lost, was based on previously published work [13].

The travel cost was estimated as the sum of the travel time incurred to attend and return home from dental appointments and the associated travel distance using recommended rates at AU $\$ 0.66$ per kilometre [26], assuming travel by car. The travel costs were assumed to be zero where the child's principle of residence is in the same suburb as the local public dental service, or if the first visit was at a school-based dental check-up for children in the intervention group.

Dental treatment costs were derived from the dental record audit and its costs estimated using the CDBS fee schedule [27]. Any dental treatment services not chargeable under the CDBS, although chargeable via the public dental service, was estimated using the Dental Weighted Activity Unit (DWAU), where 0.09 DWAU is equal to AU\$52.65 for a comprehensive oral examination.

The opportunity costs lost, which included travel and dental treatment time, was estimated using the potential mean hourly work rate of productivity loss of the primary carer. For an hourly work rate not stated or work status of being unemployed, the national minimum wage for adults at AU\$17.7 per hour was applied [28].

For the cost-analysis, there is a chargeable service fee for travel to provide dental services. In reality, the travel costs from a healthcare perspective to perform the intervention would be significantly less. Therefore, one-way sensitivity analysis was performed whereby only one service fee for travel to provide services per study visit day was applied, rather than multiple units of the service fee for travel for each child in the intervention group.

\subsection{Data Analysis}

All data was entered and cleaned using Excel 365 (Microsoft Corporation ${ }^{\mathrm{TM}}$, Washington, DC, USA). Summary descriptive statistics, two-group mean-comparison tests ( $t$-tests) and two-group proportion tests ( $z$-tests) were performed using Stata IC Version 12 (Statacorp ${ }^{\mathrm{TM}}$, College Station, TX, USA), where statistical significance was determined at $p<0.05$. A one-sample proportion test ( $z$-test) was performed to test the null hypothesis $\left(\mathrm{H}_{0}=0.75\right)$ for the child retention rate.

\section{Results}

A total of 331 children participated: 168 children in the intervention and 163 children in standard care. Tables 1 and 2 describes the summary statistics for the social circumstances and dental history, with a mean follow-up period of 2.4 years $( \pm 0.3$ standard deviation (SD)) and non-participation rate of $51 \%$ for the intervention group. The mean age for the intervention and standard care groups was 6.2 years $( \pm 2.8 \mathrm{SD})$ and 7.3 years $( \pm 2.8 \mathrm{SD})$, respectively $(p<0.001)$. The participation recruitment process fell short of the target sample size of 288 per group $(<58.3 \%)$, and thus affected the study's statistical power. 
Table 1. Summary statistics, cultural background, demographic and social profile of children.

\begin{tabular}{|c|c|c|c|}
\hline Demographics and Social History & $\begin{array}{c}\text { Standard Care } \\
(n=163) \\
n(\%)\end{array}$ & $\begin{array}{c}\text { Intervention } \\
\quad(n=168) \\
n(\%)\end{array}$ & $p$-Value \\
\hline Mean Age (SD) (y) & $7.3(2.8)$ & $6.2(2.8)$ & $0.001 *$ \\
\hline \multicolumn{4}{|l|}{ Sex } \\
\hline Female & $92(56 \%)$ & $78(46 \%)$ & Reference \\
\hline Male & $71(44 \%)$ & $90(54 \%)$ & 0.068 \\
\hline \multicolumn{4}{|l|}{ Cultural Background (ASCCEG Classification) } \\
\hline Not Stated & $5(3 \%)$ & $9(5 \%)$ & - \\
\hline Multiracial & $22(13 \%)$ & $15(9 \%)$ & - \\
\hline Oceanian & $60(37 \%)$ & $20(12 \%)$ & - \\
\hline Southern and Eastern European & $14(9 \%)$ & $9(5 \%)$ & - \\
\hline North-West European & $12(7 \%)$ & $3(2 \%)$ & - \\
\hline North-East Asian & $2(1 \%)$ & $8(4 \%)$ & - \\
\hline South-East Asian & $5(3 \%)$ & $9(5 \%)$ & - \\
\hline Southern and Central Asian & $27(17 \%)$ & $46(27 \%)$ & - \\
\hline North African and Middle Eastern & $16(10 \%)$ & $44(26 \%)$ & - \\
\hline Sub-Saharan African & $0(0 \%)$ & $5(3 \%)$ & - \\
\hline \multicolumn{4}{|c|}{ Principal Place of Residence (SEIFA Classification) } \\
\hline $1-5$ & $47(29 \%)$ & $153(91 \%)$ & Reference \\
\hline $6-10$ & $116(71 \%)$ & $15(9 \%)$ & $0.001 *$ \\
\hline \multicolumn{4}{|l|}{ Household Income } \\
\hline Not Stated & $24(14 \%)$ & $36(21 \%)$ & - \\
\hline$<\$ 50,000$ & $71(44 \%)$ & $77(46 \%)$ & Reference \\
\hline$\geq \$ 50,000$ & $68(42 \%)$ & $55(33 \%)$ & 0.231 \\
\hline \multicolumn{4}{|l|}{ Card-holder Status } \\
\hline Yes & $88(54 \%)$ & $77(46 \%)$ & Reference \\
\hline No & $75(46 \%)$ & $91(54 \%)$ & 0.138 \\
\hline \multicolumn{4}{|l|}{ CDBS Eligibility } \\
\hline Yes & $84(52 \%)$ & $87(52 \%)$ & Reference \\
\hline No & $79(48 \%)$ & $81(48 \%)$ & 0.962 \\
\hline \multicolumn{4}{|l|}{ Has Private Health Insurance } \\
\hline Yes & $34(21 \%)$ & $27(16 \%)$ & Reference \\
\hline No & $129(79 \%)$ & $141(84 \%)$ & 0.261 \\
\hline
\end{tabular}

Table 2. Summary statistics of the children's dental history.

\begin{tabular}{lccc}
\hline \multicolumn{1}{c}{ Dental History } & $\begin{array}{c}\text { Standard Care } \\
(\boldsymbol{n = 1 6 3 )} \\
\boldsymbol{n} \mathbf{( \% )}\end{array}$ & $\begin{array}{c}\text { Intervention } \\
(\boldsymbol{n}=\mathbf{1 6 8 )} \\
\boldsymbol{n} \mathbf{( \% )}\end{array}$ & $p$-Value \\
\hline Duration Since Last Dental Check-up & & & \\
$\quad$ Never & $33(20 \%)$ & $76(45 \%)$ & Reference \\
Had previously a dental check-up & $130(80 \%)$ & $92(55 \%)$ & $<0.001^{*}$ \\
<6 Months & $26(16 \%)$ & $36(21 \%)$ & - \\
7-12 Months & $80(49 \%)$ & $36(21 \%)$ & - \\
13-24 Months & $16(10 \%)$ & $11(6 \%)$ & - \\
>24 Months & $8(5 \%)$ & $9(5 \%)$ & - \\
\hline Is a Previous Patient with Dianella Plenty Valley Health & & & \\
Yes & $97(60 \%)$ & $49(29 \%)$ & Reference \\
No & $66(40 \%)$ & $119(71 \%)$ & $<0.001 *$ \\
\hline
\end{tabular}


Table 2. Cont.

\begin{tabular}{lccc}
\hline \multicolumn{1}{c}{ Dental History } & $\begin{array}{c}\text { Standard Care } \\
(\boldsymbol{n = 1 6 3 )} \\
n \mathbf{( \% )}\end{array}$ & $\begin{array}{c}\text { Intervention } \\
(\boldsymbol{n = 1 6 8 )} \\
\boldsymbol{n} \mathbf{( \% )}\end{array}$ & $p$-Value \\
\hline $\begin{array}{l}\text { Previous Dental Service Type } \\
\text { Not Applicable }\end{array}$ & $29(18 \%)$ & $77(46 \%)$ & - \\
$\quad \begin{array}{l}\text { Public } \\
\text { Private }\end{array}$ & $100(61 \%)$ & $54(32 \%)$ & - \\
$\quad$ Overseas & $29(18 \%)$ & $31(18 \%)$ & - \\
\hline Missed School Due to Dental Pain & $5(3 \%)$ & $6(4 \%)$ & - \\
$\quad$ Yes & $14(9 \%)$ & $14(8 \%)$ & Reference \\
$\quad$ No & $149(91 \%)$ & $154(92 \%)$ & 0.933 \\
\hline Frequency of Missing School Due to Dental Pain & & & - \\
$\quad$ Never & $149(91 \%)$ & $154(92 \%)$ & Reference \\
Sometimes & $3(2 \%)$ & $0(0 \%)$ & 0.067 \\
$\quad$ Frequently & $11(7 \%)$ & $14(8 \%)$ &
\end{tabular}

There were several characteristic dental and social history variables that had no significant difference: $\operatorname{sex}(p=0.068)$, household income $(p=0.231)$, card-holder status $(p=0.138)$, CDBS eligibility $(p=0.962)$, missed school due to dental pain $(p=0.933)$ and frequency of missing school due to pain $(p=0.067)$.

There were significant differences for the child's principle place of residence according to the SEIFA index $(p<0.001)$, if children never had a dental check-up $(p<0.001)$ and whether the child has previously used the local public dental service $(p<0.001)$. For the intervention group, there was no statistically significant difference for the child retention rate $\left(\mathrm{H}_{0}=0.75 ; p=0.954\right)$.

The EQ-5D-Y health profiles and EQ VAS data are reported in Table 3. The number of children who met the inclusion criteria was 40 for the intervention and 60 for standard care. There were no significant differences for the health dimensions of 'Mobility' $(p=0.078)$, 'Doing Usual Activities' $(p=0.547)$, 'Feeling Worried, Sad or Unhappy' $(p=0.078)$. There were significant differences for the health dimensions of 'Looking After Myself' $(p=0.021)$ and 'Having Pain or Discomfort' $(p=0.010)$. There was a higher self-rated EQ VAS score for the standard care group than the intervention group of $90.7( \pm 13.2 \mathrm{SD})$ and $81.9( \pm 18.0 \mathrm{SD})$, respectively.

Table 3. The EQ-5D-Y health profiles and the EQ Visual Analogue Scale (EQ VAS) data of children in the study.

\begin{tabular}{|c|c|c|c|c|}
\hline \multicolumn{2}{|c|}{ EQ-5D-Y Dimension } & \multirow{3}{*}{$\begin{array}{c}\begin{array}{c}\text { Standard Care } \\
(\boldsymbol{n}=\mathbf{6 0 )} \\
\boldsymbol{n}(\mathbf{\%})\end{array} \\
58(97 \%) \\
2(3 \%)\end{array}$} & \multirow{3}{*}{$\begin{array}{c}\text { Intervention } \\
\left(\begin{array}{c}n=40) \\
n(\%)\end{array}\right. \\
35(87 \%) \\
5(13 \%)\end{array}$} & \multirow{3}{*}{$\begin{array}{c}p \text {-Value } \\
\text { Reference } \\
0.078\end{array}$} \\
\hline Mobility & No Problems & & & \\
\hline & Problems & & & \\
\hline \multirow{2}{*}{ Looking After Myself } & No Problems & $56(93 \%)$ & $31(77 \%)$ & Reference \\
\hline & Problems & $4(7 \%)$ & $9(23 \%)$ & $0.021 *$ \\
\hline \multirow[t]{2}{*}{ Doing Usual Activities } & No Problems & $56(93 \%)$ & $36(90 \%)$ & Reference \\
\hline & Problems & $4(7 \%)$ & $5(10 \%)$ & 0.547 \\
\hline \multirow[t]{2}{*}{ Having Pain or Discomfort } & No Problems & $52(87 \%)$ & $26(65 \%)$ & Reference \\
\hline & Problems & $8(13 \%)$ & $14(35 \%)$ & $0.010 *$ \\
\hline \multirow[t]{2}{*}{ Feeling Worried, Sad or Unhappy } & No Problems & $52(87 \%)$ & $29(72 \%)$ & Reference \\
\hline & Problems & $8(13 \%)$ & $11(28 \%)$ & 0.078 \\
\hline \multicolumn{5}{|l|}{ EQ VAS Data } \\
\hline Mean (SD) & & 90.7 (13.2) & $81.9(18.0)$ & - \\
\hline 25th Percentile & & 85 & 70 & - \\
\hline 50th Percentile & & 97 & 82.5 & - \\
\hline 75th Percentile & & 100 & 100 & - \\
\hline
\end{tabular}

* statistically significant $p<0.05$. 
All other comparisons are reported in Table 4. In terms of weight status, significant differences between 'Healthy Weight' and 'Unhealthy Weight' were found $(p=0.005)$. There were no significant differences for untreated dental caries at $d / D_{3}-d / D_{6}$ level at baseline or untreated dental caries in dentine at the two-year follow-up. There were significant differences for non-cavitated dental caries for the deciduous $(p=0.001)$ and permanent $(p=0.010)$ teeth at baseline. Significant differences were observed for all cost categories except for dental treatment costs (unadjusted).

Table 4. The children's weight and untreated dental caries status and dental care characteristics of children in the study.

\begin{tabular}{|c|c|c|c|}
\hline Health Status and Dental Care Characteristics & $\begin{array}{c}\text { Standard Care } \\
\begin{array}{c}(n=163) \\
n(\%)\end{array}\end{array}$ & $\begin{array}{c}\text { Intervention } \\
\quad(n=168) \\
n(\%)\end{array}$ & $p$-Value \\
\hline \multicolumn{4}{|l|}{ Weight Status } \\
\hline Unknown & $3(2 \%)$ & $8(5 \%)$ & - \\
\hline Below Healthy Weight & $33(20 \%)$ & $22(13 \%)$ & - \\
\hline Above Healthy Weight & $13(8 \%)$ & $26(15 \%)$ & - \\
\hline Well Above Healthy Weight & $17(10 \%)$ & $40(24 \%)$ & - \\
\hline Healthy Weight & $97(60 \%)$ & $72(43 \%)$ & Reference \\
\hline Unhealthy Weight & $63(39 \%)$ & $88(55 \%)$ & $0.005^{*}$ \\
\hline \multicolumn{4}{|l|}{$\begin{array}{l}\text { Untreated Dental Caries Baseline } \\
\text { (Modified ICDAS II [20] }\end{array}$} \\
\hline $\mathrm{d} 2$ & $2.40(3.1)$ & $1.40(2.2)$ & 0.001 * \\
\hline d3-6 & $0.93(1.8)$ & $1.39(2.5)$ & 0.056 \\
\hline D2 & $1.07(2.1)$ & $0.57(1.3)$ & 0.010 * \\
\hline D3-6 & $0.19(0.6)$ & $0.18(0.7)$ & 0.873 \\
\hline \multicolumn{4}{|l|}{ Untreated Cavitated Dental Caries at Follow-Up } \\
\hline $\mathrm{d}$ & $0.38(1.1)$ & $0.64(1.7)$ & 0.094 \\
\hline $\mathrm{D}$ & $0.04(0.2)$ & $0.05(0.3)$ & 0.590 \\
\hline \multicolumn{4}{|l|}{ Referred for Dental Treatment } \\
\hline Yes & $75(46 \%)$ & $104(62 \%)$ & Reference \\
\hline No & $88(54 \%)$ & $64(38 \%)$ & $0.004 *$ \\
\hline \multicolumn{4}{|l|}{ Received Surgical Dental Treatment } \\
\hline Yes & $46(28 \%)$ & $41(24 \%)$ & Reference \\
\hline No & $117(72 \%)$ & $127(76 \%)$ & 0.430 \\
\hline \multicolumn{4}{|l|}{ Child Retention Rates at Follow-Up } \\
\hline Yes & $71(95 \%)$ & $76(75 \%)$ & Reference \\
\hline No & $4(5 \%)$ & $25(25 \%)$ & $0.001 *$ \\
\hline Null Hypothesis Test (Intervention Only) & - & $75 \%$ & 0.954 \\
\hline Dental Treatment Time (SD) (min) & $115.1(120.6)$ & $79.6(79.1)$ & $0.002 *$ \\
\hline Number of Dental Visits (SD) & $3.2(2.5)$ & $2.6(1.7)$ & $0.011^{*}$ \\
\hline Travel Costs (SD) (AU\$) & $19.0(27.3)$ & $8.0(10.9)$ & $0.001 *$ \\
\hline Dental Treatment Time Cost (SD) (AU\$) & $40.4(41.8)$ & $28.0(28.4)$ & $0.002 *$ \\
\hline \multicolumn{4}{|l|}{ Dental Treatment Cost (SD) (AU\$) } \\
\hline Unadjusted & $695.4(627.8)$ & $585.1(516.5)$ & 0.081 \\
\hline Adjusted & - & $517.6(517.4)$ & $0.005^{*}$ \\
\hline \multicolumn{4}{|l|}{ Total Society Cost (SD) (AU\$) } \\
\hline Unadjusted & $754.7(674.9)$ & $621.2(547.8)$ & 0.049 * \\
\hline Adjusted & - & $533.8(548.8)$ & 0.003 * \\
\hline
\end{tabular}




\section{Discussion}

This study demonstrated consistent findings from our previous work that the intervention increases utilisation of dental services for children who never had a dental check-up [13] and achieved the target null hypothesis. It appears that a school-based dental check-up intervention may be more effective than traditional school-based dental screening to address child retention rates.

There is some evidence the CDBS Australian federal dental program may not have a major impact on increasing the utilisation of dental services in the target population. Corroborating observations note that many children in the intervention group never had a dental check-up $(p<0.05)$ compared to standard care. Government reviews of the program indicate that there is a steady increasing rates of dental services utilisation, but it remained proportionally low, from $29.5 \%$ to $37.9 \%$, between 2014 and 2018 [4].

There were similar self-reported symptoms for missed school attendance due to dental pain and frequency by children in both groups. However, the social impacts on general health were more apparent for older children in the intervention group for the health dimensions of 'Looking After Myself' and 'Having Pain or Discomfort'. These observations were also supported with lower self-rated health profiles from the EQ VAS scale.

Previous research reported that dental caries is associated with both high and low BMI [17]. Similarly, in our study, we found that there was a significant difference for healthy weight and unhealthy weight status. This could be explained by the higher levels of untreated cavitated dental caries in the deciduous teeth for children in the intervention group since an unhealthy diet is a major risk factor for dental caries risk [29].

Our research identified that children in the intervention group were more likely to require dental treatment $(p<0.05)$, which was not observed in our previous study. However, the cost-analysis is consistent with the observed lower total society costs for the intervention group compared to standard care [13]. The findings have important implications from a health economics and public policy perspective. Firstly, the implementation of subsidised publicly funded dental care, such as the CDBS, may not address dental care utilisation issues, particularly, for children from low-income families.

School-based dental programs, such as those observed in our study, have several advantages. It can address inequities associated with the utilisation of dental services for children. This may lead to a reduction of school absenteeism due to dental pain, improve quality of life, and reduce the prevalence of unhealthy weight if children become regular users of dental services. However, the components of the program would need to be carefully considered.

We know there is enough evidence that school dental screening may have limited benefits to society. Should school-based dental programs focus on preventive interventions or should it include a dental treatment component as well? Our work presented here is a replication study, which demonstrated that the intervention could be integrated well using the existing local public dental service.

Other school-based preventive dental programs such as the application of fluoride varnish and fissure sealants have demonstrated clinical and economic benefits [30-34], with some evidence that fluoride varnish programs may be more cost-effective than fissure sealants [34]. Our study can be enhanced feasibly by incorporating fluoride varnish applications, which is efficacious to prevent dental caries [35] and is cost-effective from an Australian healthcare perspective [36].

\section{Limitations}

In resource-constrained Australian public dental services, school-based preventive dental programs are likely to yield larger health and economic benefits at the population-level than school-based dental programs that have a dental treatment component, relative to the costs incurred. It should be noted that our intervention may not be translatable to other countries due to differences in healthcare systems.

The findings of this study should be interpreted with caution, with regards to the study's suboptimal sample size and its effect on statistical power. The intervention described used a passive 
recruitment approach, which has resulted in lower participation rates than estimated. This observation was also found in our previous work [13]. However, the consistent findings of the primary and secondary aim of this replication study are indicative of relative validity.

One of the robust advantages of this study was the ability to observe changes to untreated cavitated dental caries and the associated total society costs associated with local public dental services provided to children mimicked a 'natural' experiment, i.e., there were not strict guidelines required by dental practitioners to manage the child's oral health.

Therefore, any observed effects on dental caries outcomes can be generalisable to real-world scenarios. It is plausible that having mandatory requirements for the primary carers to attend their child's school-based dental check-up appointment influenced high child retention rates. However, there are several important study weaknesses.

Firstly, untreated cavitated dental caries outcomes were censored and assumed to be diagnosed within dentine. Thus, the total observed outcomes of dental caries at the two-year follow-up are likely to be underestimated since the diagnoses were not performed by calibrated dental practitioners. Our study was not focused on dental caries outcomes, but we recognise that a future study should address this methodological flaw.

Secondly, we do not know if children who participated in the study may have sought dental treatment externally from the local public dental service being referred to. Consequently, the total society costs incurred could be underestimated, especially if a child required dental treatment under general anaesthetic, where the costs for a hospital admission is estimated to be between AU $\$ 2500$ to AU $\$ 8000$ in the private sector, or the mean cost of AU\$3029 in the public sector [37].

Thirdly, when healthcare services are free or low cost, which was the case for children in this study, there is a concern of increased consumption of healthcare compared to when healthcare services have high out-of-pocket expenses, commonly referred in health economics as a 'moral hazard' [38]. But public dental services generally have societal pressure to provide dental care to more people in the eligible population to reduce waiting lists, thereby mitigating this risk.

A targeted school-based dental check-up program may further reduce costs and improve efficiencies by minimising low-value care that is often provided in standard care. For example, preventive services that are commonly provided at a routine dental check-up at a dental clinic includes oral prophylaxis and scaling, which has been shown to have limited health benefits [39]. Families would also need to make a trade-off between attending additional dental appointments for their child to receive dental treatment or going to work.

\section{Conclusions}

This validation study demonstrated that a targeted school-based dental check-up program has a child retention rate of $75 \%$ and increases the utilisation of dental services for children from low-income families. Children receiving dental treatment services from the intervention or standard care group had similar untreated cavitated dental caries outcomes at baseline and at the two-year follow-up. Additional investigations are required to evaluate the health economic impact of a school-based dental check-up program compared to standard care to inform whether the intervention should be implemented more extensively.

Author Contributions: Conceptualization, T.M.N., S.K. and M.V.M.; methodology, T.M.N.; formal analysis, T.M.N.; project administration, T.M.N.; writing—original draft preparation, T.M.N. and B.C.; writing-review and editing, T.M.N., B.C., S.K. and M.V.M.; funding acquisition, T.M.N., S.K. and M.V.M. All authors have read and agreed to the published version of the manuscript.

Funding: This research was co-funded by The Wrigley Company Foundation ADAF Community Service Grants Community Service Grant 2016.

Acknowledgments: We acknowledge the contributions of following individuals: Clare Ericson (C.E.), My-Linh Ngo (M.-L.N.) and Diana Petrovski (D.P.) for assistance in data collection and project administration, Hanny Calache (H.C.) for the calibration of dental examiners, in-kind contributions for funding dental treatment provided by Dianella Plenty Valley Health, and academic support from the eviDent Foundation, the University of Melbourne, 
La Trobe University and Deakin University, the Department of Education and Training Victoria, and our preschool and primary school project partners involved in this project.

Conflicts of Interest: The authors declare no conflict of interest. The funders had no role in the design of the study; in the collection, analyses, or interpretation of data; in the writing of the manuscript, or in the decision to publish the results.

\section{Appendix A}

- Child's age

- Child's ethnicity

- Height (cm)

- Weight $(\mathrm{kg})$

- Is your child eligible for dental care in private practice under the Child Dental Benefits Schedule?

- When was the last time your child had a dental check-up?

- If applicable, where was your child's last dental check-up completed?

- Has the participant had a history of care with Plenty Valley Community Health?

- Is the participant a Concession or Health Care Card holder?

- Does your child have private health insurance?

- Has your child missed attending school due to dental pain?

- If applicable, how frequently has your child missed school due to dental pain?

- What is your employment status?

- If applicable, what is your hourly wage?

- What is your child's family annual household income?

Figure A1. The 20-min semi-structured interview collected information for the following variables and questions.

Table A1. Adapted from the EQ-5D-Y questionnaire by the EuroQol Group.

\begin{tabular}{ll}
\hline EQ-5D-Y & \\
\hline Describing your health TODAY & \\
\hline Under each heading, please tick the ONE box that best describes your health & $\square$ \\
TODAY & $\square$ \\
\hline Mobility (walking about) & $\square$ \\
I have no problems walking about & $\square$ \\
I have some problems walking about & $\square$ \\
I have a lot of problems walking about & $\square$ \\
\hline Looking after myself & \\
I have no problems washing or dressing myself & $\square$ \\
I have some problems washing or dressing myself & $\square$ \\
I have a lot of problems washing or dressing myself & $\square$ \\
\hline Doing usual activities (for example, going to school, hobbies, sports, playing, doing & $\square$ \\
things with family or friends) & $\square$ \\
I have no problems doing my usual activities & $\square$ \\
I have some problems doing my usual activities & $\square$ \\
I have a lot of problems doing my usual activities & $\square$ \\
\hline Having pain or discomfort & $\square$ \\
I have no pain or discomfort & $\square$ \\
I have some pain or discomfort & $\square$ \\
I have a lot of pain or discomfort & \\
\hline Feeling worried, sad or unhappy & \\
I am not worried, sad or unhappy & \\
I am a bit worried, sad or unhappy & \\
I am very worried, sad or unhappy & \\
\hline
\end{tabular}


Table A2. Classification of the child's weight status based on the US Centres for Disease Control and Prevention.

\begin{tabular}{cc}
\hline Weight Category & Percentile Range \\
\hline Below a healthy weight & Less than the 5th percentile \\
Healthy Weight & 5th percentile to less than the 85th percentile \\
Above a healthy weight & 85th to less than the 95th percentile \\
Well above a healthy weight & Equal to or greater than the 95th percentile \\
\hline
\end{tabular}

\begin{tabular}{|c|c|c|}
\hline & $\begin{array}{l}\text { The best health } \\
\text { you can imagine }\end{array}$ & \\
\hline & $\bar{\equiv}$ & 100 \\
\hline & $\overline{\overline{\overline{\bar{E}}}}$ & 95 \\
\hline & $\overline{\overline{\overline{\bar{E}}}}$ & 90 \\
\hline & $\overline{\bar{\equiv}}$ & 85 \\
\hline & $\overline{\overline{\overline{\overline{ }}}}$ & 80 \\
\hline & $\overline{\overline{\overline{\overline{ }}}}$ & 75 \\
\hline & $\bar{\equiv}$ & 70 \\
\hline & $\overline{\underline{ }}$ & 65 \\
\hline This line is numbered from 0 to 100 . & $\overline{\bar{\equiv}}$ & 60 \\
\hline 100 means the best health you can imagine. & $\overline{\overline{\bar{E}}}$ & 55 \\
\hline - Please mark an $X$ on the line that shows how good or bad your & $\overline{\bar{\equiv}}$ & 50 \\
\hline health is TODAY. & $\overline{\overline{\bar{E}}}$ & 45 \\
\hline & $\overline{\overline{\bar{E}}}$ & 4 \\
\hline & 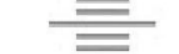 & 35 \\
\hline & $\overline{\overline{ }}$ & \\
\hline & $\bar{\equiv}$ & 30 \\
\hline & $\overline{\bar{\equiv}}$ & 25 \\
\hline & $\bar{\equiv}$ & 20 \\
\hline & $\overline{\bar{\equiv}}$ & 15 \\
\hline & $\overline{\bar{\equiv}}$ & 10 \\
\hline & $\begin{array}{l}\text { The worst health } \\
\text { you can imagine }\end{array}$ & 5 \\
\hline
\end{tabular}

Figure A2. How good is your health TODAY. Adapted from the EQ-5D-Y questionnaire by the EuroQol Group. 
Child ID:

Age:

\begin{tabular}{|c|c|c|c|c|c|c|c|c|c|c|c|c|c|c|c|c|}
\hline \multirow{3}{*}{$\begin{array}{l}\text { Surf } \\
\text { ace }\end{array}$} & \multicolumn{14}{|c|}{ Upper Right } & \multicolumn{2}{|c|}{ Upper Left } \\
\hline & 18 & 17 & 16 & 15 & 14 & 13 & 12 & 11 & 21 & 22 & 23 & 24 & 25 & 26 & 27 & 28 \\
\hline & & & & 55 & 54 & 53 & 52 & 51 & 61 & 62 & 63 & 64 & 65 & & & \\
\hline
\end{tabular}

\begin{tabular}{lllllllll}
\hline $\mathrm{M}$ & & & & & & \\
\hline $\mathrm{O}$ & & $\square$ & $\square$ & $\square$ & $\square$ & $\square$ & $\square$ & \\
\hline $\mathrm{D}$ & & & & & & & \\
\hline $\mathrm{B}$ & & & & & \\
\hline $\mathrm{L}$ & & & & & & \\
\hline & & & & & \\
\hline & Lower Right & & & & \\
\hline
\end{tabular}

\begin{tabular}{lllllllllllllllll} 
Surf & 48 & 47 & 46 & 45 & 44 & 43 & 42 & 41 & 31 & 32 & 33 & 34 & 35 & 36 & 37 & 38 \\
\cline { 4 - 5 } & & 85 & 84 & 83 & 82 & 81 & 71 & 72 & 73 & 74 & 75 & &
\end{tabular}

\begin{tabular}{|c|c|c|c|c|c|c|}
\hline M & & & & & & \\
\hline $\mathrm{O}$ & ㅁ & ㅁ & $\square$ & ㅁ & 口 & ㅁ \\
\hline D & & & & & & \\
\hline B & & & & & & \\
\hline L & & & & & & \\
\hline
\end{tabular}

Restoration and Sealant Codes

$0=$ Not sealed or restored

1 = Sealant, partial

2 = Sealant, full

$3=$ Tooth coloured restoration

$4=$ Amalgam restoration

$5=$ Stainless steel crown

$6=$ Porcelain, gold, PFM crown or veneer $6=$ Extensive distinct cavity with visible dentine

$7=$ Lost or broken restoration

$8=$ Temporary restoration

\section{Caries Codes}

$0=$ Sound tooth surface

$1=$ First visual change in enamel

$2=$ Distinct visual change in enamel

$3=$ Enamel breakdown, no dentine visible

$4=$ Dentinal shadow (not cavitated into dentine)

$5=$ Distinct cavity with visible dentine

\section{Missing Teeth}

96 = Surface excluded (one surface only)

$97=$ Extracted due to caries

$98=$ Missing for other reason

$99=$ Unerupted

Figure A3. Modified international caries detection and assessment system (ICDAS II).

\section{References}

1. $\quad$ Peres, M.A.; Macpherson, L.M.D.; Weyant, R.J.; Daly, B.; Venturelli, R.; Mathur, M.R.; Listl, S.; Celeste, R.K.; Guarnizo-Herreño, C.C.; Kearns, C.; et al. Oral diseases: A global public health challenge. Lancet 2019, 394, 249-260. [CrossRef]

2. Do, L.; Spencer, J.E. Oral Health of Australian Children: The National Child Oral Health Study 2012-14; University of Adelaide Press: Adelaide, Australia, 2016. [CrossRef]

3. Nguyen, T.M.N. Is the Current Model of Public Dental Care Promoting the Oral Health of Young Children in Australia? Australian Healthcare and Hospitals Association, Deeble Institute: Canberra, Australia, 2017. Available online: https:/ahha.asn.au/publication/health-policy-issue-briefs/deeble-institute-issues-brief-no20-current-model-public (accessed on 13 October 2020). 
4. Australian Government, Department of Health. Report on the Fourth Review of the Dental Benefits Act 2008; Australian Government: Canberra, Australia, 2019. Available online: https://www1.health.gov.au/internet/ main/publishing.nsf/Content/Dental_Report_on_the_Review_of_the_Dental_Benefits_Act_2008 (accessed on 13 October 2020).

5. Arora, A.; Khattri, S.; Ismail, N.; Kumbargere Nagraj, S.; Prashanti, E. School dental screening programmes for oral health. Cochrane Database Syst. Rev. 2019, 8, CD012595. [CrossRef] [PubMed]

6. Joury, E.; Bernabe, E.; Sabbah, W.; Nakhleh, K.; Gurusamy, K. Systematic review and meta-analysis of randomised controlled trials on the effectiveness of school-based dental screening versus no screening on improving oral health in children. J. Dent. 2017, 58,1-10. [CrossRef] [PubMed]

7. Nguyen, T.M.N.; Hsueh, Y.-S.; Morgan, M.; Mariño, R.; Koshy, S. Economic Evaluation of a Pilot Targeted School-Based Dental Check-up Program. JDR Clin. Trans. Res. 2017, 2, 214-222. [CrossRef]

8. Milsom, K.; Blinkhorn, A.; Worthington, H.; Threlfall, A.; Buchanan, K.; Kearney-Mitchell, P.; Tickle, M. The effectiveness of school dental screening: A cluster-randomized control trial. J. Dent. Res. 2006, 85, 924-928. [CrossRef]

9. Wainwright, P.; Thomas, J.; Jones, M. Health promotion and the role of the school nurse: A systematic review. J. Adv. Nurs. 2000, 32, 1083-1091. [CrossRef]

10. Lineberry, M.J.; Ickes, M.J. The role and impact of nurses in American elementary schools: A systematic review of the research. J. Sch. Nurs. 2015, 31, 22-33. [CrossRef]

11. Greyson, D.; Vriesema-Magnuson, C.; Bettinger, J.A. Impact of school vaccination mandates on pediatric vaccination coverage: A systematic review. CMAJ Open 2019, 7, e524-e536. [CrossRef]

12. Fisher-Owens, S.A.; Gansky, S.A.; Platt, L.J.; Weintraub, J.A.; Soobader, M.-J.; Bramlett, M.D.; Newacheck, P.W. Influences on children's oral health: A conceptual model. Pediatrics 2007, 120, e510-e520. [CrossRef]

13. Nguyen, T.M.N.; Morgan, M.; Koshy, S.; Mathew, S.; Lew, S. Revisiting the value of school dental check-up programs. Health Care 2015, 50, 70.

14. Armfield, J.M.; Spencer, A.J.; Stewart, J.F. Dental fear in Australia: Who's afraid of the dentist? Aus. Dent. J. 2006, 51, 78-85. [CrossRef]

15. Rebelo, M.A.B.; Rebelo Vieira, J.M.; Pereira, J.V.; Quadros, L.N.; Vettore, M.V. Does oral health influence school performance and school attendance? A systematic review and meta-analysis. Int. J. Clin. Pediatr. Dent. 2019, 29, 138-148. [CrossRef] [PubMed]

16. Ruff, R.R.; Senthi, S.; Susser, S.R.; Tsutsui, A. Oral health, academic performance, and school absenteeism in children and adolescents: A systematic review and meta-analysis. J. Am. Dent. Assoc. 2019, 150, 111-121. [CrossRef] [PubMed]

17. Hooley, M.; Skouteris, H.; Boganin, C.; Satur, J.; Kilpatrick, N. Body mass index and dental caries in children and adolescents: A systematic review of literature published 2004 to 2011. Syst. Rev. 2012, 21, 57. [CrossRef] [PubMed]

18. Australian Bureau of Statistics. Census of Population and Housing: Socio-Economic Indexes for Areas (SEIFA), Australia, 2011; Australian Bureau of Statistics: Canberra, Australia, 2013. Available online: https://www.abs. gov.au/ausstats/abs@.nsf/DetailsPage/2033.0.55.0012011 (accessed on 13 October 2020).

19. Lemeshow, S. Adequacy of Sample Size in Health Studies; John Wiley \& Sons Limited: West Sussex, UK, 1990.

20. International Caries Detection and Assessment System (ICDAS) Coordinating Committee. Criteria Manual: International Caries Detection and Assessment System (ICDAS II). Available online: https://iccms-web.com/ uploads/asset/5ccb149905404942610729.pdf (accessed on 13 October 2020).

21. Australian Bureau of Statistics. Australian Standard Classification of Cultural and Ethnic Groups. Available online: https://www.abs.gov.au/ausstats/abs@.nsf/mf/1249.0 (accessed on 13 October 2020).

22. EuroQol Group. EQ-5D-Y User Guide. Available online: https://euroqol.org/wp-content/uploads/2019/10/ EQ-5D-Y-User-Guide.pdf (accessed on 13 October 2020).

23. Kreimeier, S.; Greiner, W. EQ-5D-Y as a Health-Related Quality of Life Instrument for Children and Adolescents: The Instrument's Characteristics, Development, Current Use, and Challenges of Developing Its Value Set. Value Health 2019, 22, 31-37. [CrossRef]

24. NSW Health. Healthy Weight Calculator for Children and Teenagers. Available online: https://pro. healthykids.nsw.gov.au/calculator (accessed on 13 October 2020). 
25. Australian Dental Association. The Australian Schedule of Dental Services and Glossary: Twelfth Edition. Available online: https://www.ada.org.au/Dental-Professionals/Publications/Schedule-and-Glossary/TheAustralian-Schedule-of-Dental-Services-and-(1)/Australian_Schedule_and_Dental_Glossary_2015_FA2 W.aspx (accessed on 13 October 2020).

26. Australian Tax Office. Cents per Kilometre Method. Available online: https://www.ato.gov.au/Business/ Income-and-deductions-for-business/Deductions/Deductions-for-motor-vehicle-expenses/Cents-perkilometre-method (accessed on 13 October 2020).

27. Fair Work Commission. National Minimum Wage Order 2016. Available online: https: //www.fwc.gov.au/awards-agreements/minimum-wages-conditions/annual-wage-reviews/annualwage-review-2015-16/national (accessed on 13 October 2020).

28. Australian Government, Department of Health. The Child Dental Benefits Schedule. Available online: https://www1.health.gov.au/internet/main/publishing.nsf/Content/childdental (accessed on 13 October 2020).

29. Harris, R.; Nicoll, A.D.; Adair, P.M.; Pine, C.M. Risk factors for dental caries in young children: A systematic review of the literature. Community Dent. Health 2004, 21, 71-85. [PubMed]

30. Bergstrom, E.K.; Lingstrom, P.; Hakeberg, M.; Gahnberg, L.; Skold, U.M. Caries and costs: An evaluation of a school-based fluoride varnish programme for adolescents in a Swedish region. Community Dent. Health 2016, 33, 138-144. [CrossRef]

31. Sköld, U. Approximal caries increment in relation to baseline approximal caries prevalence among adolescents in Sweden with and without a school-based fluoride varnish programme. Community Dent. Health 2016, 33, 281-285. [CrossRef]

32. Griffin, S.; Naavaal, S.; Scherrer, C.; Griffin, P.M.; Harris, K.; Chattopadhyay, S. School-based dental sealant programs prevent cavities and are cost-effective. Health Aff. (Millwood) 2016, 35, 2233-2240. [CrossRef]

33. Griffin, S.O.; Naavaal, S.; Scherrer, C.; Patel, M.; Chattopadhyay, S. Evaluation of School-Based Dental Sealant Programs: An Updated Community Guide Systematic Economic Review. Am. J. Prev. Med. 2017, 52, 407-415. [CrossRef] [PubMed]

34. Neidell, M.; Shearer, B.; Lamster, I.B. Cost-Effectiveness Analysis of Dental Sealants versus Fluoride Varnish in a School-Based Setting. Caries Res. 2016, 50, 78-82. [CrossRef]

35. Marinho, V.; Worthington, H.; Walsh, T.; Clarkson, J. Fluoride varnishes for preventing dental caries in children and adolescents. Cochrane Database Syst. Rev. 2013, 11, CD002279. [CrossRef] [PubMed]

36. Nguyen, T.M.N.; Tonmukayakul, U.; Warren, E.; Cartwright, S.; Liew, D. A Markov cost-effective analysis of biannual fluoride varnish for preventing dental caries in permanent teeth over a 70-year time horizon. Health Promot. J. Austr. 2020, 31, 177-183. [CrossRef] [PubMed]

37. Rogers, J.; Delany, C.; Wright, C.; Roberts-Thomson, K.; Morgan, M. What factors are associated with dental general anaesthetics for Australian children and what are the policy implications? A qualitative study. BMC Oral Health 2018, 18, 174. [CrossRef] [PubMed]

38. Newhouse, J. Consumer-Directed Health Plans and the RAND Health Insurance Experiment. Health Aff. 2004, 23, 107-113. [CrossRef] [PubMed]

39. Lamont, T.; Worthington, H.V.; Clarkson, J.E.; Beirne, P.V. Routine scale and polish for periodontal health in adults. Cochrane Database Syst. Rev. 2018, 27, CD004625. [CrossRef]

Publisher's Note: MDPI stays neutral with regard to jurisdictional claims in published maps and institutional affiliations.

(C) 2020 by the authors. Licensee MDPI, Basel, Switzerland. This article is an open access article distributed under the terms and conditions of the Creative Commons Attribution (CC BY) license (http://creativecommons.org/licenses/by/4.0/). 